\title{
Impact of rosuvastatin treatment on reduction of thrombus burden in rat acute inferior vena cava stenosis
}

\author{
Kun-Chen Lin ${ }^{1 \dagger}$, Hung-I Lu ${ }^{2 \dagger}$, Yung-Lung Chen ${ }^{3}$, Tzu-Hsien Tsai ${ }^{3}$, Li-Teh Chang ${ }^{4}$, Steve Leu ${ }^{5}$, Shu-Yuan Hsu ${ }^{6}$, \\ Cheuk-Kwan Sun ${ }^{7}$, Han-Tan Chai ${ }^{3}$, Hsueh-Wen Chang ${ }^{9}$, Chia-Lo Chang ${ }^{8}$, Hong-Hwa Chen ${ }^{8^{*}}$ and Hon-Kan Yip ${ }^{1,5^{*}}$
}

\begin{abstract}
Background: This study tested the hypothesis that rosuvastatin reduces thrombus burden through inhibiting inflammation and suppressing reactive oxygen species (ROS) generation in an inferior vena cava stenosis (IVCST)-induced deep vein thrombosis (DVT) rat model.

Methods: 12 -week-old male Sprague-Dawley rats $(n=24)$ were equally divided into sham control (group 1: laparotomy only), IVC (group 2: IVC stenosis), and IVC $C_{S T}$ + rosuvastatin $(20 \mathrm{mg} / \mathrm{kg} /$ day, orally after induction of IVC stenosis) (group 3). IVC diameter was measured by days 0 and 14 and the right hindlimb thickness was measured by day 0,7 , and 14 prior to scarifying the animals.

Results: The results showed significantly increased IVC diameter and hindlimb thickness in group 2 than in groups 1 and 3 , and significantly increased in group 3 than in group 1 by day 14 after the procedure (all $p<0.001$ ). Additionally, WBC count and prevalence of helper T cells, cytotoxic $T$ cells, regulatory $T$ cells, and early and late apoptotic mononuclear cells (MNCS) in circulation were significantly higher in group 2 than in group 1, and were significantly suppressed in group 3 after treatment (all $p<0.001$ ). Furthermore, inflammation at cellular (CD68+ cells) and protein (MMP-9, TNF-a) levels, oxidative stress (oxidized protein) and reactive oxygen species (NOX-1, NOX-2) in IVC also showed similar changes as those of immune cells in circulation among the three groups (all $p<0.01$ ).

Conclusion: Rosuvastatin treatment significantly reduced IVC thrombus burden through inhibiting inflammatory response and oxidative stress in a rodent model of DVT.
\end{abstract}

\section{Introduction}

Venous thromboembolic disease (VTED) (i.e., pulmonary embolism and deep vein thrombosis) affects approximately 100 persons in a population of 100,000 per year [1]. The incidence increases with age, rising exponentially from less than 5 per 100,000 per year in those under 15 of age to over 500 per 100,000 per year in those aged over 80 years [1]. VTED consists of a divergent spectrum of clinical disorders, from asymptomatic deep vein thrombosis (DVT) to symptomatic DVT and life-threatening pulmonary

\footnotetext{
* Correspondence: honghwa.chen@gmail.com; han.gung@msa.hinet.net ${ }^{\dagger}$ Equal contributors

${ }^{8}$ Division of Colorectal Surgery, Department of Surgery, Kaohsiung Chang Gung Memorial Hospital and Chang Gung University College of Medicine, Kaohsiung, Taiwan

'Department of Anesthesiology, Kaohsiung Chang Gung Memorial Hospital and Chang Gung University College of Medicine, Kaohsiung, Taiwan Full list of author information is available at the end of the article
}

embolism (PE) [1-3]. DVT that occurs or extends above the knee (i.e., proximal DVT) carry a significant risk of propagation to form acute or chronic recurrent $\mathrm{PE}$, resulting in acute cardiac or respiratory compromise or pulmonary arterial hypertension and, in severe cases, death [1-7]. In addition, VTED may itself be associated with significant morbidity through the development of post-thrombotic syndrome (PTS) [8].

Studies have extensively renewed the concept of Virchow's triad that describes the three factors, i.e., hypercoagulability, stasis, and endothelial injury as the fundamental contributors to the development of venous thrombosis [9-11]. Actually, extensive works have shown that venous and arterial thrombosis involves more complicated mechanisms other than that included in Virchow's triad [9-11]. Accordingly, more detailed investigation into the mechanism underlying Virchow's triad has been recommended [9-11]. In fact, it has 
been reported that the pathogenesis of VTED also includes various molecular-cellular components [9-11]. For instance, injury of the endothelial cells and stimulation of the monocytes lead to the release of inflammatory cytokines [11]. The pro-inflammatory mediators including bacterial lipopolysaccharide, and the cytokines interleukin-1 and tumor necrosis factor- $\alpha$ (TNF- $\alpha$ ), in turn, induce and augment the pro-coagulant activity (i.e., thrombin generation) [11-14]. Interestingly, a recent clinical trial, i.e., the secondary analyses of the JUPITER trial, in which 17,802 apparently healthy subjects were randomly allocated to receive either rosuvastatin daily or placebo, provided evidence that statin therapy reduced the incidence of DVT [15]. Although the mechanism underlying the therapeutic effect remains uncertain, the findings suggest a positive association between inflammation and DVT. For clarifying the potential role of rosuvastain therapy in reducing venothrombosis and molecular-cellular mechanisms involved, a rodent model of inferior vena cava (IVC) stenosis to create a DVT scenario was utilized in the current study.

\section{Methods \\ Ethics}

All animal experimental procedures were approved by the Institute of Animal Care and Use Committee at Kaohsiung Chang Gung Memorial Hospital and performed in accordance with the Guide for the Care and Use of Laboratory Animals (NIH publication No. 85-23, National Academy Press, Washington, DC, USA, revised 1996).

\section{Animal model of acute inferior vena cava thrombosis and treatment}

Pathogen-free, adult male Sprague-Dawley (SD) rats weighing 375-400 g (Charles River Technology, BioLASCO Taiwan Co. Ltd., Taiwan) were equally divided into three groups ( $\mathrm{n}=8$ in each group): Group 1 (Sham control, SC): laparotomy only; Group 2 (DVT only): laparotomy + IVC stenosis $\left(\mathrm{IVC}_{\mathrm{ST}}\right)$; and Group 3 (DVT + Rosu): laparotomy $+\mathrm{IVC}_{\mathrm{ST}}+$ rosuvastatin $(20 \mathrm{mg} / \mathrm{kg} /$ day $)$ by gavage. The dosage of rosuvastatin for the animals was based on our recent study [16]. The treatment was initiated just after the IVC stenosis procedure and continued for 14 days. The rats were sacrificed on day 14 after laparotomy and measurement of the IVC diameter.

Additionally, for assessing acute phase of thrombus formation and changes of IVC diameter at day 2 after DVT induction, another 8 rats in each group were utilized and they were sacrificed at day 2 after parameters were collected.

Laparotomy and IVC stenosis were performed after anesthesia of the rats by inhalation of $2.0 \%$ isoflurane. Briefly, the rat was placed in a supine position on a warming pad at $37^{\circ} \mathrm{C}$ with the abdomen shaved. Under sterile conditions, the abdomen was opened and IVC was exposed, followed by tying a 23 gauge needle over the IVC just below the level of left renal vein with 4-0 silk in each rat. Additionally, to avoid the formation of collateral circulation that would attenuate the thrombusburden formation, the larger side branches were ligated and those observable small side branches/capillaries were carefully cauterized during the procedure. After the procedure, the abdominal wound was closed and the animal was allowed to recover from anesthesia in a portable animal intensive care unit (ThermoCare ${ }^{\oplus}$ ) for 24 hours.

\section{Assessment of IVC diameter and palm thicknes}

After the first laparotomy prior to IVC stenosis, the diameter of IVC was measured at three levels $1 \mathrm{~mm}$ apart. Additionally, by day 14 just prior to the sacrificing the animals, the diameter of IVC below the stricture level with an interval of $1 \mathrm{~mm}$ was measured at three levels again after second laparotomy. The parameters were summated and then divided by 3 for each rat at the two time points, respectively.

To determine the severity of hindlimb edema caused by IVC obstruction, the hindlimb thickness (i.e. the distance between the sole and instep) in each rat was measured with a digital caliper at days 0,7 and 14 just before sacrificing the animals.

\section{Circulating White Blood Cell (WBC) count and flow cytometric quantification of helper T cells, cytotoxic T cells, and regulatory $\mathrm{T}$ cells (Tregs)}

By days 2, 6 and 14 prior to sacrificing the animals (i.e., $n=8$ for each group in each time interval to be sacrificed), peripheral blood mononuclear cells (PBMCs) were obtained from the tail vein using a 27 \# needle in each rat for determining the WBC count. In addition, PBMCs and splenocytes $\left(1.0 \times 10^{6}\right.$ cells) were triple-stained with FITCanti-CD3 (BioLegend), PE-anti-CD8a (BD Bioscience), and $\mathrm{PE}-\mathrm{Cy}^{\mathrm{rm}} 5$ anti-CD4 (BD bioscience). To identify CD ${ }^{+} \mathrm{CD} 25^{+}$Foxp $^{+}$Tregs, PBMCs and splenocytes were triple-stained with Alexa Fluor ${ }^{\circ}$ 488-anti-CD25 (BioLegend), PE-anti-Foxp3 (BioLegend), and PE-Cy ${ }^{\mathrm{rm}} 5$ antiCD4 (BD bioscience) according to the manufacturer's protocol on the use of the Foxp3 Fix/Perm buffer set. The numbers of $\mathrm{CD}^{+} \mathrm{CD}^{+}$helper $\mathrm{T}$ cells, $\mathrm{CD}^{+} \mathrm{CD}^{+}$cytotoxic $\mathrm{T}$ cells, and $\mathrm{CD} 4^{+} \mathrm{CD} 25^{+} \mathrm{Foxp}^{+}$Tregs were analyzed using flow cytometry (FC500, Beckman Coulter).

\section{Isolation of splenocytes and harvesting of IVC specimens}

Splenocytes were obtained by homogenization of the spleen using a Tenbroeck tissue grinder followed by passage through a $0.4-\mathrm{mm}$-pore-size cell strainer to obtain a single cell suspension. Splenocytes were then suspended in RPMI and separated by Ficoll-paque ${ }^{\mathrm{Tm}}$ Plus (GE Healthcare). 
The IVC was collected and cut into pieces, some of which were fixed with OCT (Tissue-Tek) for immunohistochemical (IHC)/immunofluorescent (IF) staining. Other pieces were either fixed in $4 \%$ paraformaldehyde/ $0.1 \%$ glutaradehyde PBS solution before being embedded in paraffin blocks for hematoxylin-eosin staining or stored at $-80^{\circ} \mathrm{C}$ for protein analyses.

\section{Western blot analysis of IVC distal to stenosis}

Equal amounts $(10-30 \mu \mathrm{g})$ of protein extracts from the IVC were loaded and separated by SDS-PAGE using $8-10 \%$ acrylamide gradients. Following electrophoresis, the separated proteins were transferred electrophoretically to a polyvinylidene difluoride (PVDF) membrane (Amersham Biosciences). Nonspecific proteins were blocked by incubating the membrane in blocking buffer (5\% nonfat dry milk in T-TBS containing $0.05 \%$ Tween 20 ) overnight. The membranes were incubated with monoclonal antibodies against polyclonal antibodies against TNF- $\alpha$ (1: 1000, Cell Signaling), matrix metalloproteinase (MMP)-9(1:5000, Abcam), NADPH oxidase (NOX)-1 (1:1500, Sigma ) and NOX-2 (1:500, Sigma). Signals were detected with horseradish peroxidase (HRP)-conjugated goat anti-mouse, -rat, or -rabbit IgG.

The Oxyblot Oxidized Protein Detection Kit was purchased from Chemicon (S7150). The procedure of 2,4-dinitrophenylhydrazine (DNPH) derivatization was carried out on $6 \mu \mathrm{g}$ of protein for 15 minutes according to the manufacturer's instructions. One-dimensional electrophoresis was carried out on $12 \%$ SDS/polyacrylamide gel after DNPH derivatization. Proteins were transferred to nitrocellulose membranes which were then incubated in the primary antibody solution (anti-DNP 1: 150) for two hours, followed by incubation with the second antibody solution (1:300) for one hour at room temperature. The washing procedure was repeated eight times within 40 minutes.

Immunoreactive bands were visualized by enhanced chemiluminescence (ECL; Amersham Biosciences), which was then exposed to Biomax L film (Kodak). For quantification, ECL signals were digitized using Labwork software (UVP). For oxyblot protein analysis, a standard control was loaded on each gel.

\section{Immunofluorescent (IF) and immunohistochemical (IHC) studies}

IF staining was performed for the examination of CD68+ cells in peri-IVC area using respective primary antibody with irrelevant antibody being used as control. Three sections of the IVC specimen were analyzed in each rat. For quantification, three randomly selected HPFs $(200 \mathrm{x})$ were analyzed in each section. The mean number of cells per HPF for each animal was then determined by summation of all numbers divided by 9 . An
IHC-based scoring system was adopted for the semiquantitative analysis of thrombomodulin expression in endothelial cells of IVC (i.e. intimal layer) as a percentage of thrombomodulin in endothelial cells (score of positively-stained thrombomodulin in endothelial cells: $0=$ no stain $\% ; 1=<15 \% ; 2=15 \sim 25 \% ; 3=25 \sim 50 \% ; 4=$ $50 \sim 75 \%$; $5=>75 \%-100 \% /$ per HPF in endothelial cells in IVC). The analysis was performed in a blinded fashion.

\section{Histopathological study of thrombus burden in IVC distal} to the level of stenosis at Day 14 after the procedure

Hematoxylin and eosin ( $\mathrm{H} \& \mathrm{E}$ ) staining for light microscopic analysis was used for studying the thrombus burden inside IVC. Three serial sections of IVC $3 \mathrm{~mm}$ apart were prepared at $4 \mu \mathrm{m}$ thickness by Cryostat (Leica CM3050S). The integrated area $\left(\mu \mathrm{m}^{2}\right)$ of thrombus in the slides was calculated using Image Tool 3 (IT3) image analysis software (University of Texas, Health Science Center, San Antonio, UTHSCSA; Image Tool for Windows, Version 3.0, USA). Three selected sections were quantified for each animal. Three randomly selected high-power fields (HPFs) (100 x) were analyzed in each section. After determining the number of pixels in each thrombus area per HPF, the numbers of pixels obtained from the three HPFs were summated. The procedure was repeated in two other slides for each animal. The mean pixel number per HPF for each animal was then determined by summating all pixel numbers and dividing by 9 . The mean the integrated area $\left(\mu \mathrm{m}^{2}\right)$ of thrombus in IVC per HPF was obtained using a conversion factor of 19.24 ( $1 \mu^{2}$ represented 19.24 pixels).

\section{Statistical analyses}

Quantitative data are expressed as mean \pm SD. Statistical analysis was performed by ANOVA followed by Bonferroni multiple-comparison post hoc test. All analyses were conducted using SAS statistical software for Windows version 8.2 (SAS institute, Cary, NC). A probability value $<0.05$ was considered statistically significant.

\section{Results}

Serial changes of immune reactivity in circulation and spleen at days 2. 6 and 14 Day after IVC stenosis

The time courses of circulating and splenic levels of immune cells are shown in Table 1 . By day 2, the circulating level of $\mathrm{CD} 3+/ \mathrm{CD} 4+$ helper $\mathrm{T}$ cells did not differ among groups 1 (sham control), group 2 (IVC stenosis) and 3 (IVC stenosis + rosuvastatin). However, by day 6 , this biomarker was higher in groups 2 and 3 than in group 1, but it showed no difference between groups 2 and 3. Additionally, by day 14, this biomarker was significantly higher in group 2 than in groups 1 and 3, and significantly higher in group 3 than in group 1 . 
Table 1 Time courses of immune cell expressions in circulation and spleen organ

\begin{tabular}{|c|c|c|c|c|}
\hline Variables & $\begin{array}{l}\text { Sham } \\
\text { control }\end{array}$ & DVT & DVT-Rosu & p-value \\
\hline \multicolumn{5}{|c|}{$\begin{array}{l}\text { Peripheral blood-derived } \\
\text { immune cells }\end{array}$} \\
\hline \multicolumn{5}{|c|}{$\begin{array}{l}\text { CD3+/CD4+ helper } \\
\text { T cells (\%) }\end{array}$} \\
\hline Day 2 & $18.9 \pm 1.0$ & $19.5 \pm 0.9$ & $19.3 \pm 0.9$ & 0.347 \\
\hline Day 6 & $17.8 \pm 0.6^{a}$ & $24.8 \pm 0.6^{b}$ & $23.2 \pm 0.6^{b}$ & $<0.001$ \\
\hline Day 14 & $17.6 \pm 0.9^{a}$ & $24.5 \pm 0.7^{b}$ & $21.3 \pm 0.3^{c}$ & $<0.001$ \\
\hline \multicolumn{5}{|c|}{$\begin{array}{l}\text { CD3+/CD8+ cytotoxic } \\
\mathrm{T}(\%)\end{array}$} \\
\hline Day 2 & $8.9 \pm 0.4$ & $9.2 \pm 0.8$ & $9.6 \pm 0.7$ & 0.439 \\
\hline Day 6 & $8.2 \pm 0.9^{a}$ & $11.2 \pm 0.7^{b}$ & $11.1 \pm 0.6^{b}$ & $<0.02$ \\
\hline Day 14 & $8.3 \pm 1.1^{a}$ & $14.8 \pm 0.4^{b}$ & $12.1 \pm 0.5^{c}$ & $<0.001$ \\
\hline \multicolumn{5}{|c|}{$\begin{array}{l}\text { CD4 + CD25+ Foxp3+ } \\
\text { Tregs (\%) }\end{array}$} \\
\hline Day 2 & $2.1 \pm 0.3$ & $2.3 \pm 0.1$ & $2.1 \pm 0.1$ & 0.478 \\
\hline Day 6 & $2.1 \pm 0.2^{\mathrm{a}}$ & $3.0 \pm 0.03^{b}$ & $2.7 \pm 0.06^{c}$ & $<0.01$ \\
\hline Day 14 & $2.2 \pm 0.3^{\mathrm{a}}$ & $3.9 \pm 0.2^{b}$ & $3.1 \pm 0.16^{c}$ & $<0.001$ \\
\hline \multicolumn{5}{|c|}{$\begin{array}{l}\text { Spleen-derived immune } \\
\text { cells }\end{array}$} \\
\hline \multicolumn{5}{|c|}{$\begin{array}{l}\text { CD3+/CD4+ helper } \\
\text { T cells (\%) }\end{array}$} \\
\hline Day 2 & $20.5 \pm 0.1$ & $20.7 \pm 1.2$ & $21.2 \pm 1.4$ & 0.641 \\
\hline Day 6 & $20.8 \pm 0.1$ & $21.8 \pm 0.4$ & $21.5 \pm 0.7$ & 0.668 \\
\hline Day 14 & $21.5 \pm 0.1$ & $21.7 \pm 0.5$ & $21.1 \pm 0.6^{c}$ & 0.485 \\
\hline \multicolumn{5}{|c|}{$\begin{array}{l}\text { CD3+/CD8+ cytotoxic } \\
T(\%)\end{array}$} \\
\hline Day 2 & $13.9 \pm 0.9$ & $14.5 \pm 0.4$ & $14.2 \pm 1.2$ & 0.397 \\
\hline Day 6 & $14.3 \pm 0.3^{\mathrm{a}}$ & $15.8 \pm 0.2^{b}$ & $15.4 \pm 0.1^{b}$ & $<0.05$ \\
\hline Day 14 & $13.6 \pm 0.9^{a}$ & $16.8 \pm 0.4^{b}$ & $14.3 \pm 0.2^{a}$ & $<0.008$ \\
\hline \multicolumn{5}{|c|}{$\begin{array}{l}\text { CD4 + CD25+ Foxp3+ } \\
\text { Tregs (\%) }\end{array}$} \\
\hline Day 2 & $7.7 \pm 0.3^{\mathrm{a}}$ & $9.0 \pm 0.3^{b}$ & $8.4 \pm 0.4^{a, b}$ & $<0.02$ \\
\hline Day 6 & $7.9 \pm 0.3^{a}$ & $9.4 \pm 0.5^{b}$ & $9.5 \pm 0.6^{b}$ & $<0.01$ \\
\hline Day 14 & $7.5 \pm 0.3^{a}$ & $12.9 \pm 0.4^{b}$ & $9.2 \pm 0.5^{c}$ & $<0.001$ \\
\hline
\end{tabular}

Data are expressed as $\%$ of mean \pm SD.

DVT = deep vein thrombosis; Rosu = rosuvastatin

Sham control = group 1, DVT = group 2, DVT-Rosu = group 3.

All statistical analyses were performed by one-way ANOVA, followed by Bonferroni multiple comparison post hoc test. Letters $\left({ }^{a}, \mathrm{~b}, \mathrm{C}\right)$ indicate significance (at 0.05 level).

By days 2, 6 and 14 after DVT induction, the circulating levels of $\mathrm{CD} 3+/ \mathrm{CD} 8+$ cytotoxic $\mathrm{T}$ cells showed an identical pattern of $\mathrm{CD} 3+/ \mathrm{CD} 4+$ helper $\mathrm{T}$ cells among the three groups in these different time intervals, respectively.

By days 2, the circulating level of CD4 + CD25 + Foxp3+ Tregs, an index of immune down-regulation, was similar among the three groups. However, by days 6 and 14, the circulating levels of this parameter showed an identical pattern of $\mathrm{CD} 3+/ \mathrm{CD} 4+$ helper $\mathrm{T}$ cells at the interval of day 14 among the three groups.

By days 2, 6 and 14 after DVT induction, the splenic level of $\mathrm{CD} 3+/ \mathrm{CD} 4+$ helper $\mathrm{T}$ cells showed no difference among the three groups. Additionally, by day 2, the splenic level of $\mathrm{CD} 3+/ \mathrm{CD} 8+$ cytotoxic $\mathrm{T}$ cells did not differ among the three groups. However, by day 6 and 14, the splenic level of this biomarker was significantly higher in group 2 than in groups 1 and 3, and significantly higher in group 2 than in group 1.

By day 2, the splenic level of CD4 + CD25 + Foxp3+ Tregs was significantly higher in group 2 than in group 1 , but it showed no difference between groups 2 and 3 or between groups 1 and 3. By day 6, the splenic level of this biomarker was significantly higher in groups 2 and 3 than in group 1, but it showed no difference between groups 2 and 3. By day 14, the splenic level of this biomarker was significantly higher in groups 2 and 3 than in group 1, and significantly higher in group 2 than in group 3.

\section{Circulating WBC count, early and late mononuclear cell (MNC) apoptosis in the circulation at Day 14 after IVC stenosis}

By day 2, the circulating levels of white blood cell (WBC) count and neutrophils (Figure 1B) were significantly higher in group 2 than in groups 1 and 3, and significantly higher in group 3 than in group 1 (Figure 1A). Additionally, the circulating level of lymphocytes (Figure 1C) were significantly lower in groups 2 and 3 than in group 1 , but it showed no difference between the former two groups.

By day 14, the circulating white blood cell (WBC) level was significantly higher in group 2 than in groups 1 and 3 , but it showed no difference between group 1 and group 3 (Figure 1D). However, the circulating levels of neutrophils (Figure 1E) and lymphocytes (Figure 1F) did not differ among the three groups.

By day 2, flow cytometry revealed the degrees of early (Figure 2A) and late (Figure 2B) apoptosis markers in circulating MNCs were higher in groups 2 and 3 than group 1, but it showed no difference between former two groups. Moreover, by day 14, flow cytometry revealed that the degree of early apoptosis in circulating MNCs was higher in group 2 than in groups 1 and 3, and significantly higher in group 3 than in group 1 (Figure 2C). In addition, the degree of late apoptosis of MNCs in circulation displayed an identical pattern compared to that of early apoptosis among three groups, although the incidence of late apoptosis was lower than that of early apoptosis (Figure 2D).

\section{Time courses of circulating levels of inflammatory cells}

By day 2, the flow cytometric analysis showed that the circulating level of CD11+ cells, an indicator of inflammation 

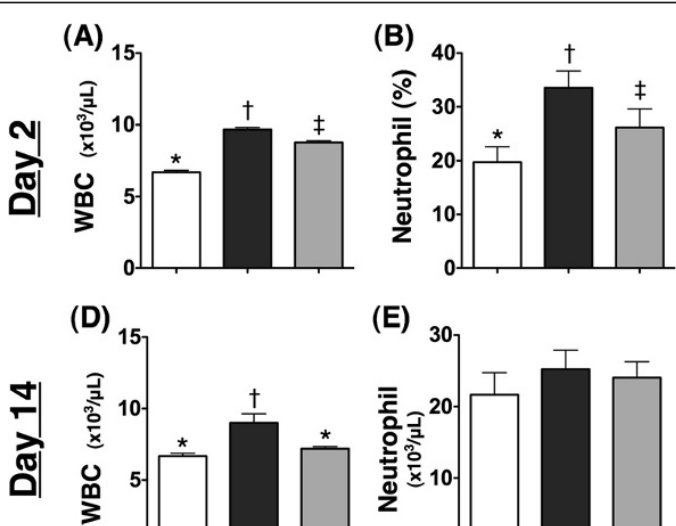

(D)

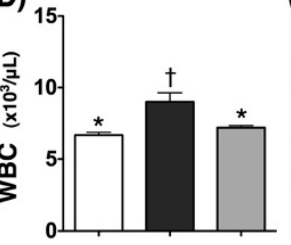

(E)

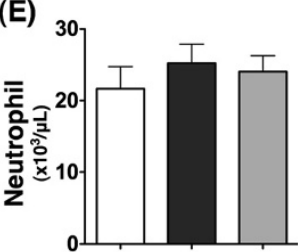

(F)
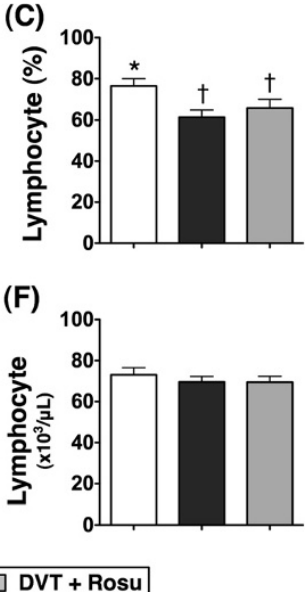

Figure 1 Levels of circulating WBC count, neutrophils and lymphocytes by days 2 and 14 after deep vein thrombosis (DVT)-induced procedure $(\mathbf{n}=\mathbf{8})$. A) Circulating level of white blood cell $(\mathrm{WBC})$ count at day 2 after DVT-induced procedure. * vs. other groups with different symbols $(*, t, \neq), p<0.001$. B) Circulating level of neutrophils at day 2 after DVT-induced procedure. * vs. Other groups with different symbols $\left({ }^{*},+, \neq\right), p<0.01$. C) Circulating level of neutrophils at day 2 after DVT-induced procedure. ${ }^{*}$ vs. other groups with different symbols $\left({ }^{*}, t\right) P<0.01$. D) circulating level of WBC count at day 14 after DVT-induced procedure. ${ }^{*}$ vs. other groups with different symbols $\left({ }^{*}, t\right), p<0.001$. E) Circulating level of neutrophils at day 14 after DVT-induced procedure. P $>0.5$. F) Circulating level of neutrophils at day 2 after DVT-induced procedure. P $>0.5$. Statistical analysis using one-way ANOVA, followed by Bonferroni multiple comparison post hoc test. Symbols $(*,+, \neq)$ indicate significance (at 0.05 level). DVT $=$ deep vein thrombosis, DVT + Rosu $=$ DVT + rosuvastatin.

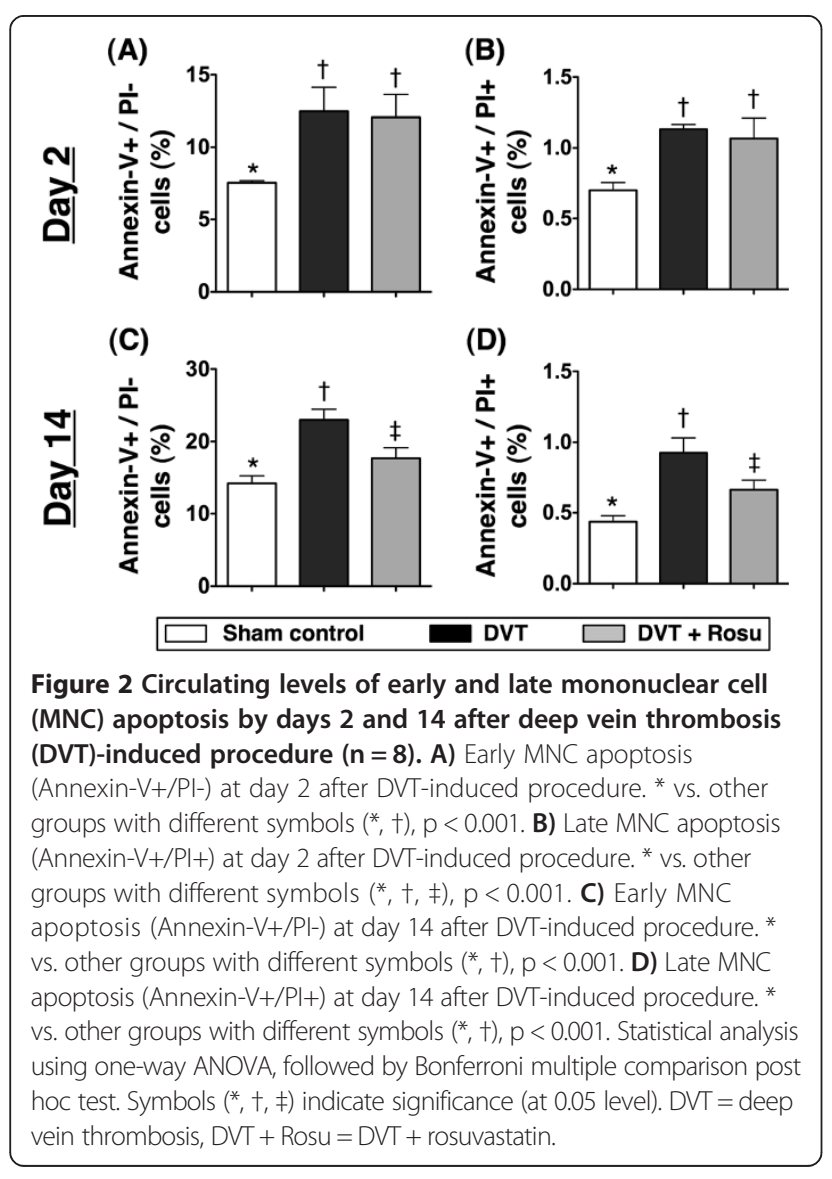

were significantly higher in groups 2 and 3 than in group 1 , but it displayed no difference between the former two groups (Figure 3A). Additionally, by days 6 and 14, this biomarker were significantly higher in group 2 than in groups 1 and 3, and significantly higher in group 3 than in group 1 (Figure $3 \mathrm{C}$ and E). Additionally, by days 2, 6 and 14, circulating level of Ly-6G + cells, another index of inflammation, exhibited an identical pattern of circulating CD14+ cells among the three groups (Figure 3B, D and F).

\section{Pathological findings by days 2 and 14 after inferior vena cava stenosis}

Figure 4 shows the results of IVC diameter, an index of IVC obstruction/swelling by day 0 (i.e., prior to IVC stenosis) and day 14 (i.e., at the end of study period) among group 1, group 2, and group 3 . On day 0 , the IVC diameter did not differ among the three groups (Figure 4B) (this parameter used in this work at day 0 was just to have a baseline for the study purpose). Besides, it also showed no difference between days 0 and 14 among the group 1 animals (Figure 4A). However, the IVC diameter was significantly increased on day 14 as compared with that on day 0 among group 2 and group 3 animals, respectively (Figure 4A). Additionally, by day 14 after IVC stenosis, this parameter was significantly higher in group 2 than in groups 1 and 3, and no different between groups 1 and 3 (Figure 4B). Thus, as compared to day 0 , the percentage of an increased in IVC diameter by day 14 was remarkably higher in group 


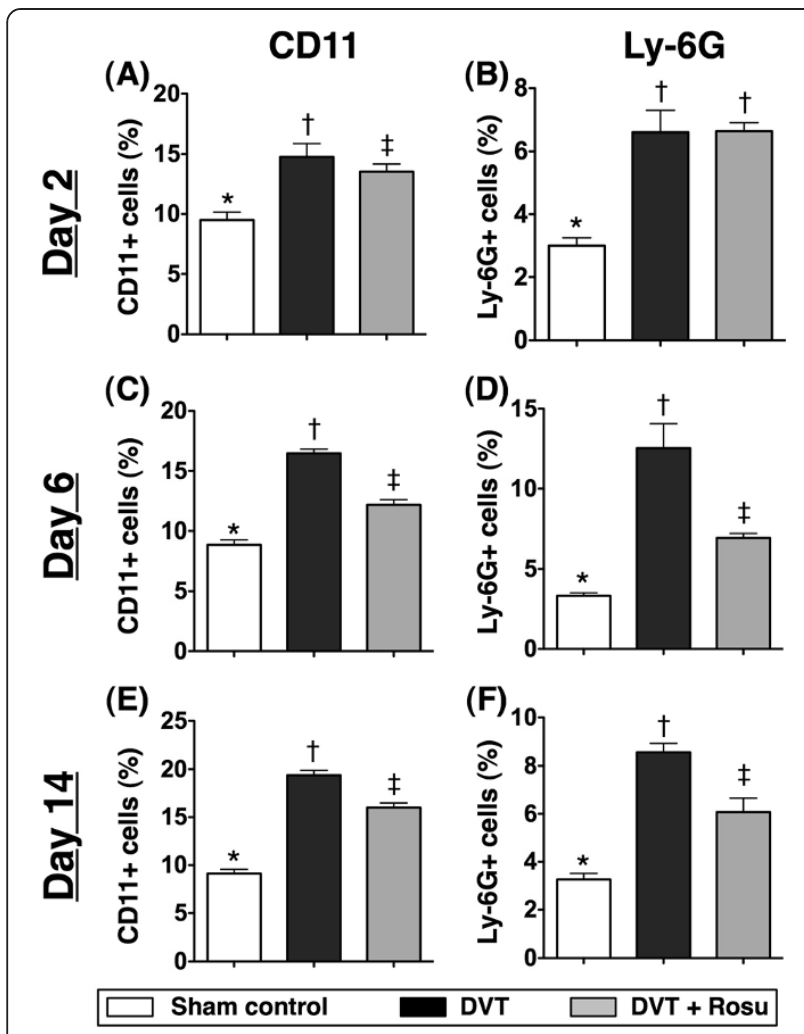

Figure 3 Flow cytometric quantification of circulating level of inflammatory cells (CD11+, Ly-6G + cells) by days 2 and 14 after deep vein thrombosis (DVT)-induced procedure $(n=8)$. A) Circulating number of CD11+ cells at day 2 after DVT-induced procedure. ${ }^{*}$ vs. other groups with different symbols $\left({ }^{*}, t, \neq\right), p<0.001$. B) Circulating number of Ly- $6 \mathrm{G}+$ cells at day 2 after DVT-induced procedure. ${ }^{*}$ vs. other groups with different symbols $\left({ }^{*},+, \neq\right), p<$ 0.001. C) Circulating number of CD11+ cells at day 6 after DVT-induced procedure. ${ }^{*}$ vs. other groups with different symbols $\left({ }^{*},+\right), p<0.001$. D) Circulating number of Ly- $6 \mathrm{G}+$ cells at day 6 after DVT-induced procedure. ${ }^{*}$ vs. other groups with different symbols $\left({ }^{*}, \dagger, \neq\right), p<0.0001$. E) Circulating number of CD11+ cells at day 14 after DVT-induced procedure. ${ }^{*}$ vs. other groups with different symbols $\left({ }^{*},+\right), p<0.001$. F) Circulating number of Ly-6G + cells at day 14 after DVT-induced procedure. ${ }^{*}$ vs. other groups with different symbols $\left({ }^{*}, t, \neq\right), p<0.0001$. DVT = deep vein thrombosis, DVT + Rosu $=$ DVT + rosuvastatin.

2 than in groups 1 and 3, and notably higher in group 3 than in group 1 (Figure $4 \mathrm{C}$ ).

As expected, the acute phase of IVC diameter (Figure 5A) and thrombus-burden formation (Figure $5 \mathrm{~B}$ ) at day 2 were significantly higher in groups 2 and 3 than in group 1, and significantly higher in group 2 than in group 3 .

Figure 6 shows that hindlimb thickness, an indictor of lower leg edema, was similar among the three groups on day 0 (Figure 6B). The thickness also showed no difference at the time points of 0,7 , and 14 day among the group 1 animals (Figure 6A). However, it was significantly increased on days 7 and 14 as compared with that on day 0 among group 2 animals (Figure 6A). Additionally, this parameter was also increased on day 7 as
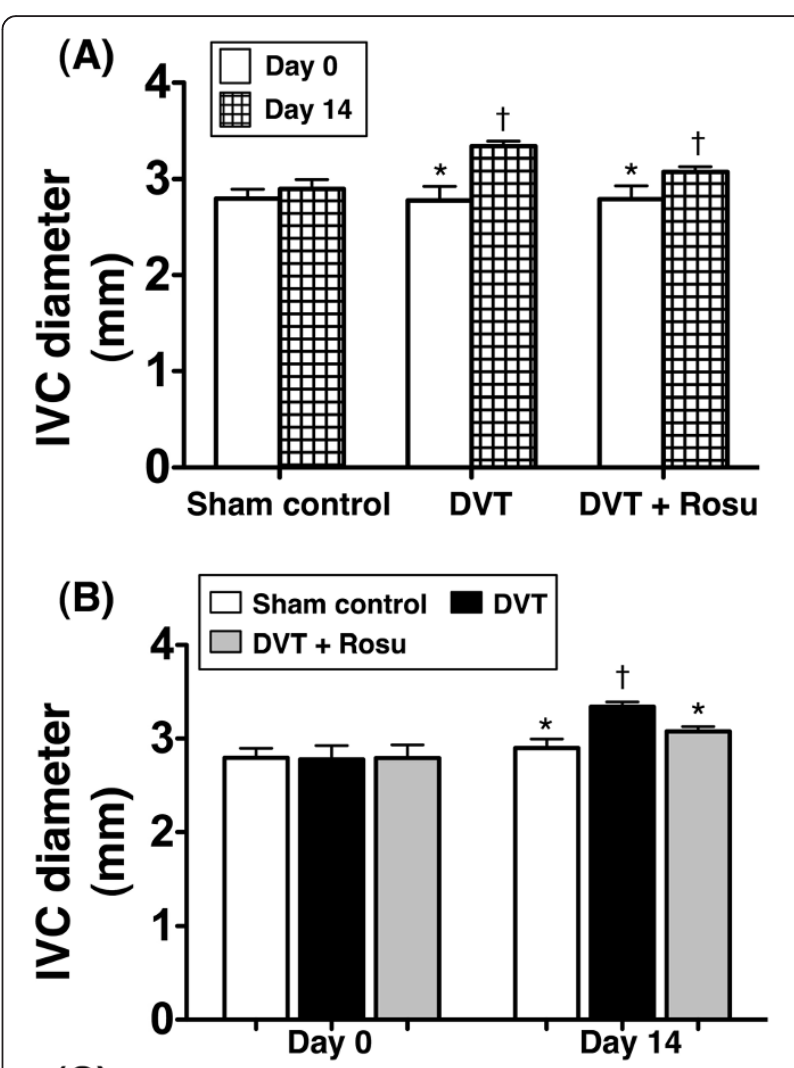

(C)

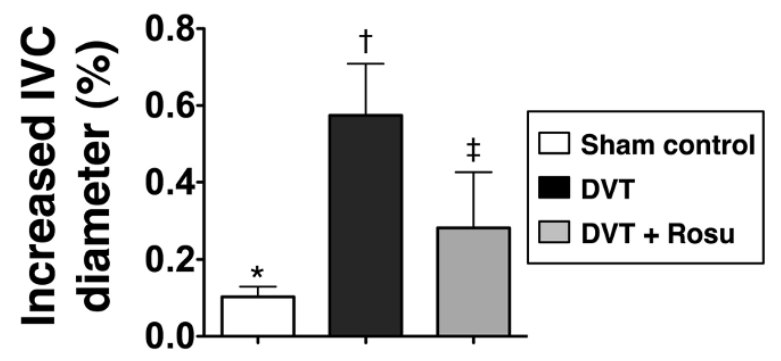

Figure 4 The diameter of inferior vena cava (IVC) at days 0 and 14 after deep vein thrombosis (DVT)-inducing procedure $(\mathbf{n}=\mathbf{8})$. A) The IVC diameter did not differ between day 0 and day 14 after DVT-induced procedure among the group 1 (sham control) animals. However, IVC diameter was significantly higher at day 14 as compared with day 0 among the group 2 (DVT) animals. * vs. day 0 , $\mathrm{p}<0.01$; Furthermore, the IVC diameter was also significantly higher at day 14 as compared with day 0 among the group 3 (DVT + Rosu) animals. ${ }^{*}$ vs. day $0, p<0.05$. B) Prior to procedure, no difference in baseline IVC diameter among group 1, group 2, and group 3 animals. However, by day 14 after DVT-induced procedure, the IVC diameter was significantly higher in group 3 than in groups 1 and 3 , and no different between groups 1 and $3 .{ }^{*}$ vs. other groups with different symbols $\left({ }^{*}, t, \neq\right), p<0.001$. C) By day 14 after DVT-induced procedure, the percentage of increased in IVC diameter was remarkably higher in group 2 than in groups 1 and 3, and notably higher in group 3 than in group $1 .{ }^{*}$ vs. other groups with different symbols $\left({ }^{*},+, \neq\right), p<0.0001$. Statistical analysis in $\mathbf{B}$ ) and $\mathbf{C}$ ) using one-way ANOVA, followed by Bonferroni multiple comparison post hoc test. Symbols $\left({ }^{*},+, \neq\right)$ indicate significance (at 0.05 level). DVT = deep vein thrombosis, DVT + Rosu = DVT + rosuvastatin. 


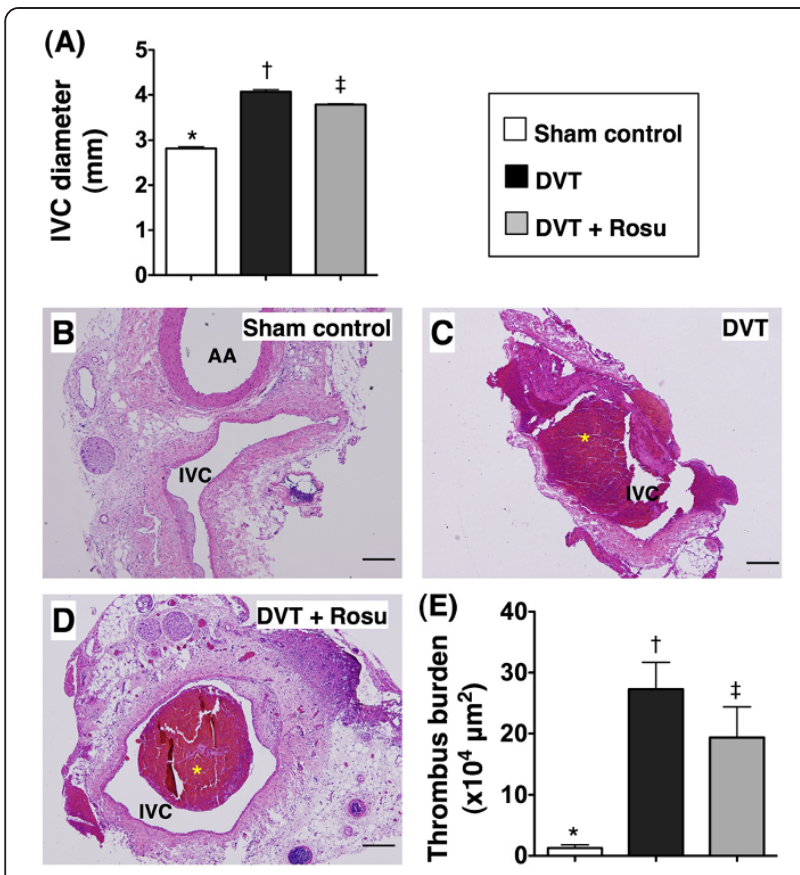

Figure 5 The diameter of inferior vena cava (IVC) and thrombus-burden formation at day 2 after deep vein thrombosis (DVT)-inducing procedure $(\mathbf{n}=\mathbf{8})$. A) The IVC diameter was significantly higher in group 2 than in groups 1 and 3, and significantly higher in group 3 than in group 1. ${ }^{*}$ vs. Other groups with different symbols $\left({ }^{*},+, \neq\right), p<0.001$. B to D) Showing the $H$ \& E staining for identification of thrombus formation in IVC in three groups. E) Analytical results of thrombus burden, * vs. other groups with different symbols $\left({ }^{*},+, \ddagger\right), p<0.0001$. Statistical analysis in $\left.\mathbf{A}\right)$ and E) using one-way ANOVA, followed by Bonferroni multiple comparison post hoc test. Symbols $(*,+, \neq)$ indicate significance (at 0.05 level). $\mathrm{DVT}=$ deep vein thrombosis, DVT + Rosu $=\mathrm{DVT}+$ rosuvastatin.

compared with that on the day 0 among group 3. However, this parameter did not differ on day 14 as compared with day 0 or day 7 . In addition, by days 7 and 14, the thickness was significantly higher in group 2 than in groups 1 and 3, and significantly higher in group 3 than in group 3 at these two time points (Figure 6B). Furthermore, the percentage of increased in hindlimb thickness was significantly higher in group 2 than in groups 1 and 3 , and notably higher in group 3 than in group 1 by days 7 and 14 after the DVT-induction procedure (Figure 6C).

Figure 7 shows the $\mathrm{H} \& \mathrm{E}$ staining of the thrombus burden in IVC of the three groups by day 14 after IVC stenosis (Figure 7A to C). The thrombus burden in IVC was significantly higher in group 2 than that in groups 1 and 3, and significantly higher in group 3 than in group 1 (Figure 7D).

Findings from Immunofluorescent (IF) and Immunohistochemical (IHC) staining on Day 14 after Inferior Vena Cava Stenosis

Figure 8 showed the results of IF and IHC staining of IVC sections distal to the level of stenosis by day 14 after
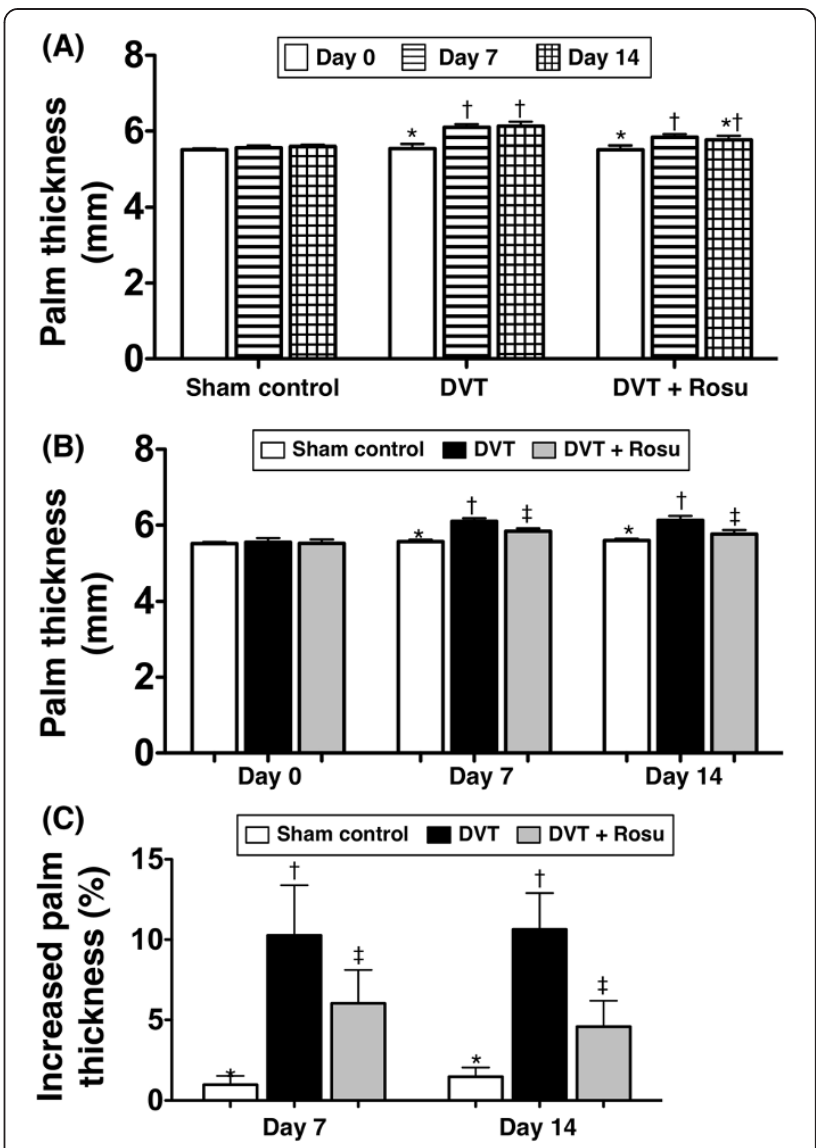

Figure 6 Hindlimb thickness at days 0, 7, and 14 after deep vein thrombosis (DVT)-inducing procedure $(\mathbf{n}=\mathbf{8})$. A) No

difference in hindlimb thickness by days 0,7 , and 14 among group 1 animals. Significantly increased hindlimb thickness on days 7 and 14 compared with day 0 , without notable difference between latter two time points among group 2 animals, $p<0.005$. The hindlimb thickness was also significantly higher on day 7 than on day 1 , but it exhibited no difference between days 0 and 14 or between days 7 and 14 among group 3 animals, $p<0.01$. B). By day 0 , no significant difference noted in hindlimb thickness among the three groups. By day 7 , hindlimb thickness significantly increased in group 2 than in groups 1 and 3, and significantly increased in group 3 than in group 1, $p<0.01$. By day 14 , hindlimb thickness significantly increased in group 2 than in groups 1 and 3, and notably increased in group 3 than in group $1, p<0.01$. C) By day 7 , the percentage of increased hindlimb thickness was significantly higher in group 2 than in groups 1 and 3 , and significantly higher in group 3 than in group $1, p<0.001$. By day 14 , the percentage of increased hindlimb thickness was significantly higher in group 2 than in groups 1 and 3, and significantly higher in group 3 than in group $1 .{ }^{*}$ vs. other groups with different symbols $(*,+, \neq)$, $\mathrm{p}<0.0001$. Statistical analysis in A), B) and C) using one-way ANOVA, followed by Bonferroni multiple comparison post hoc test. Symbols $(*,+$,$) indicate significance (at 0.05$ level). DVT = deep vein thrombosis, DVT + Rosu $=$ DVT + rosuvastatin.

the procedure. IF staining revealed that the number of peri-IVC CD68+ cells (i.e., macrophage marker), an index of inflammation, was significantly higher in group 2 than that in groups 1 and 3, and significantly higher in group 3 than in group 1 (Figure 8). Moreover, IHC staining 

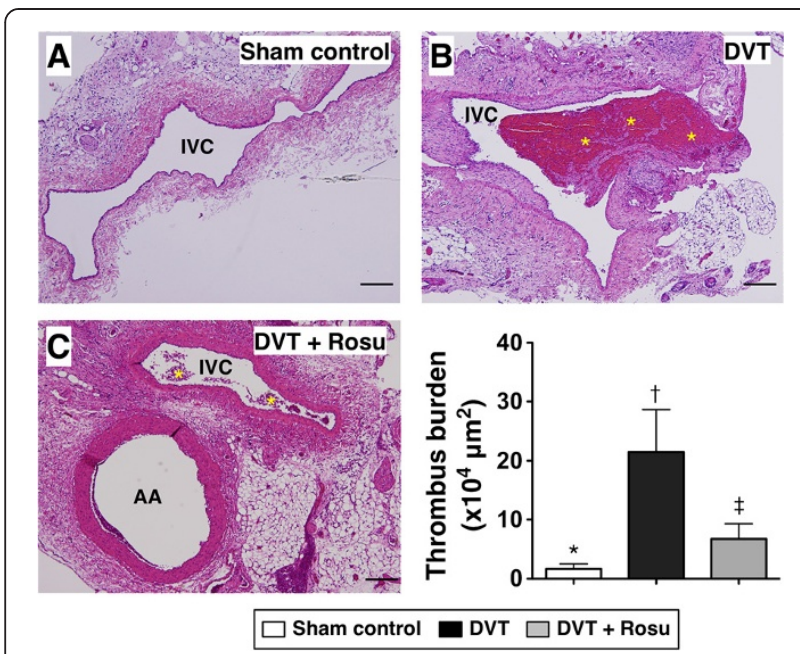

Figure 7 Thrombus burden in inferior vena cava (IVC) on day 14 after deep vein thrombosis (DVT)-inducing procedure $(n=8)$. Microscopic (40 x) morphological analysis of IVC after H \& E staining showing significantly increased thrombus burden (yellow asterisk) in group 2 (B) than in groups 1 (A) and 3 (C), and significantly increased in group 3 than in group 1. AA = abdominal aorta. ${ }^{*}$ vs. other groups with different symbols $\left({ }^{*}, \dagger, \neq\right), p<0.001$. Statistical analysis using one-way ANOVA, followed by Bonferroni multiple comparison post hoc test. Symbols $\left({ }^{*},+, \neq\right)$ indicate significance (at 0.05 level). Scale bars in right lower corner represent $200 \mu \mathrm{m}$. DVT $=$ deep vein thrombosis, DVT + Rosu = DVT + rosuvastatin.

revealed remarkably higher number of thrombomodulinpositive endothelial cells, an indicator of activated of endothelial cells, around the IVC in group 2 than that in groups 1 and 3, and significantly higher in group 3 than in group 1 (Figure 8).

Protein expressions of oxidized protein and inflammatory biomarkers at Day 14 after inferior vena cava stenosis

By day 14 after the procedure, Western blot analysis showed that the expression of oxidized protein, an indicator of oxidative stress, was significantly higher in group 2 than that in groups 1 and 3, and significantly higher in group 3 than that in group 1 (Figure 9). Besides, the protein expressions of TNF- $\alpha$ and MMP-9, two indices of inflammation, exhibited an identical pattern compared to that of oxidized protein among the three groups (Figure 10).

The protein expressions of Reactive Oxygen Species (ROS) by Day 14 after inferior vena cava stenosis

By day 14, the protein expressions of NADPH oxidase (NOX)-1 and NOX-2, two indicators of ROS, was significantly higher in group 2 than that in groups 1 and 3, and significantly higher in group 3 than that in group 1 (Figure 11).
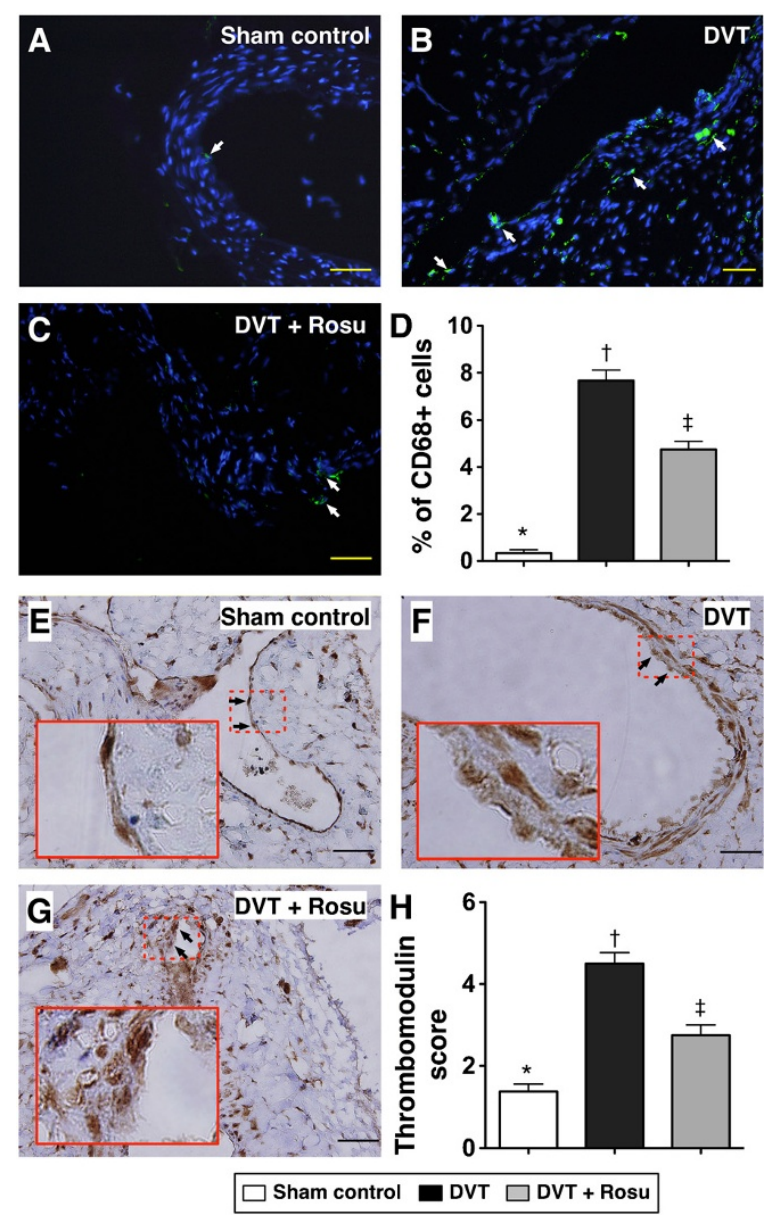

Figure 8 Immunofluorescent (IF) and immunohistochemical (IHC) staining of inferior vena cava (IVC) at day 14 after deep vein thrombosis (DVT)-inducing procedure $(n=8)$. A to $D$ ) Microscopic $(200 \mathrm{x}$ ) examination of IVC after IF staining showing significantly higher number of CD68+ cells (i.e., macrophage) in peri-IVC area (white arrows) in group 2 than in groups 1 and 3, and notably higher in group 3 than in group 1. D) * vs. other groups with different symbols $(*,+, \neq), p<0.0001$. Scale bars in right lower corner represent $50 \mu \mathrm{m}$. $\mathbf{E}$ to $\mathbf{H})$ Microscopic $(200 \mathrm{x})$ examination of IVC after IHC staining showing significantly higher number of positively stained thrombomodulin endothelial cells (i.e., intimal layer) (black arrows) in group 2 than in groups 1 and 3, and significantly higher in group 3 than in group $1 . \mathbf{H}){ }^{*}$ vs. other groups with different symbols $\left({ }^{*}, t, \neq\right), p<0.0001$. Scale bars in right lower corner represent $50 \mu \mathrm{m}$. Statistical analysis in D) and $\mathbf{H}$ ) using one-way ANOVA, followed by Bonferroni multiple comparison post hoc test. Symbols $(*,+, \ddagger)$ indicate significance (at 0.05 level). DVT = deep vein thrombosis, DVT + Rosu $=$ DVT + rosuvastatin

\section{Discussion}

One important finding in the current study is that, as compared with sham controls (i.e., SC), the diameter of IVC at days 2 and 14 after the procedure were remarkably higher in animals with IVC stricture (i.e., DVT group). Additionally, we serially measured the hindlimb thickness (i.e., at days 0, 7 and 14) and found that this parameter was notably increased in DVT animals as 


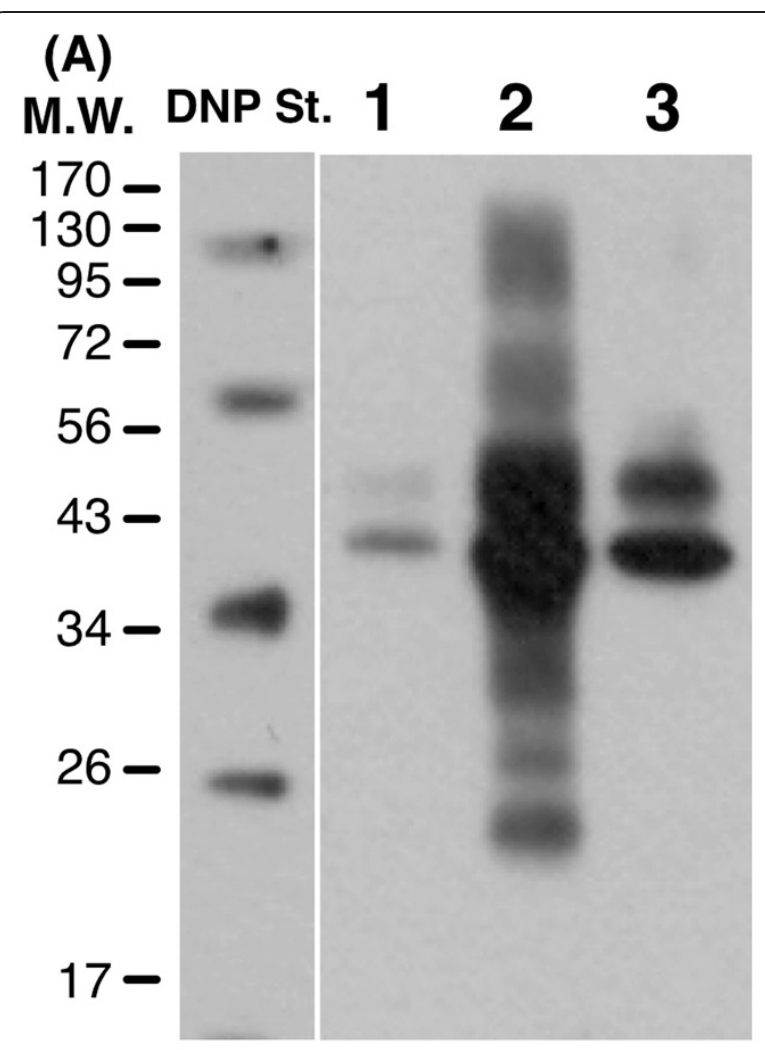

(B)

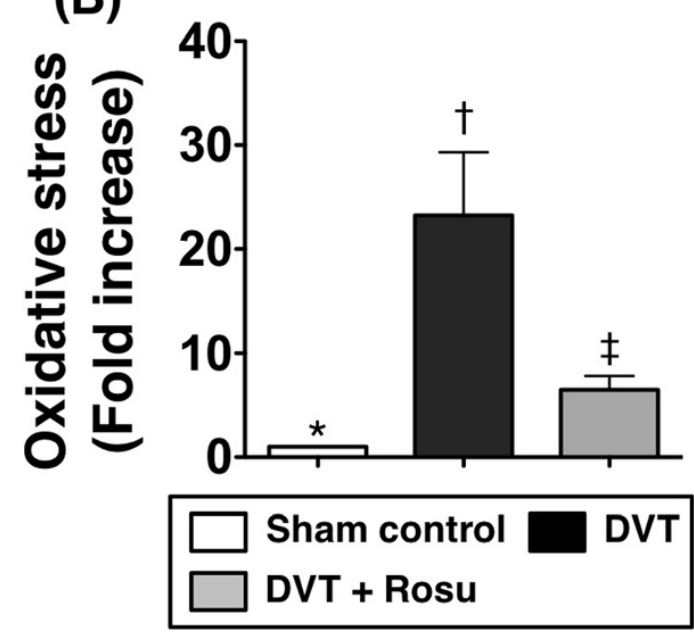

Figure 9 Protein expression of oxidative stress at day 14 after DVT-inducing procedure $(\mathbf{n}=\mathbf{8})$. A) oxidative index (protein

carbonyls) among three groups of animals ( 1 = sham control, 2 = DVT only, 3 = DVT + rosuvastatin). B) Remarkably increased expression of oxidized protein (i.e., oxidative stress) in group 2 than in groups 1 and 3 , and notably higher in group 3 than in group $1 .{ }^{*}$ vs. other groups with different symbols $(*,+, \neq), p<0.0001$. [Note: Right lane and left lane shown on the upper panel represent control oxidized molecular protein standard and protein molecular weight (M.W.) marker, respectively]. DNP $=1-3$ dinitrophenylhydrazone. Statistical analysis using one-way ANOVA, followed by Bonferroni multiple comparison post hoc test. Symbols $(*,+, \ddagger)$ indicate significance (at 0.05 level). $\mathrm{DVT}=$ deep vein thrombosis, DVT + Rosu $=\mathrm{DVT}+$ rosuvastatin
(A)
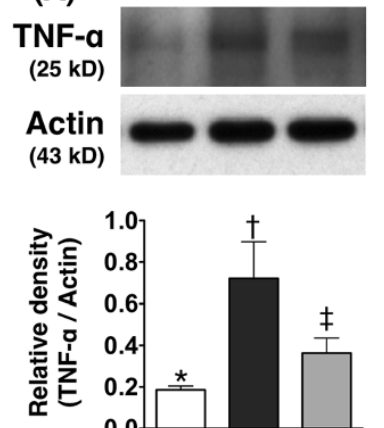

$\square$ Sham control
(B)

MMP-9

(92 kD)

Actin

(43 kD)

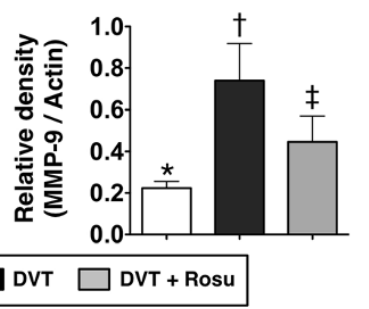

Figure 10 Protein expressions of inflammatory biomarkers at day 14 after DVT-inducing procedure $(n=8)$. A) Significantly higher protein expression of tumor necrosis factor (TNF)-a in group 2 than in groups 1 and 3, and significantly higher in group 3 than in group 1. ${ }^{*}$ vs. other groups with different symbols $\left({ }^{*},+, \ddagger\right), p<0.01$. B) Notably enhanced protein expression of matrix metalloproteinase (MMP)-9 in group 2 than in groups 1 and 3, and significantly higher in group 3 than in group 1. ${ }^{*}$ vs. other groups with different symbols $\left({ }^{*},+, \neq\right), p<0.01$. Statistical analysis in $\left.\mathbf{A}\right)$ and $\left.\mathbf{B}\right)$ using one-way ANOVA, followed by Bonferroni multiple comparison post hoc test. Symbols $(*,+\neq)$ indicate significance (at 0.05 level). DVT = deep vein thrombosis, DVT + Rosu $=\mathrm{DVT}+$ rosuvastatin.

compared to that of SC animals by days 7 and 14 . To the best of our knowledge, there are no animal model (i.e., at the upright models, such us primates) in where this can be successfully assessed in serial time intervals after DVT procedure. We suggest that this is a novel and important clinical-relevant finding. Furthermore, another intriguing histopathological finding is that the thrombus burden (i.e., the thrombus cross-sectional area inside IVC) was notably higher in DVT group than that in SC group. The results suggest that our thrombus formation model was successfully created through stenosis of IVC. The most important finding of this study is that all of these anatomical and histopathological changes in DVT group were substantially reversed in DVT animals after receiving rosuvastatin treatment for two weeks. Two clinical studies, one recent randomized placebo-control trial [15] and one previous retrospective study with a large sample size [17], have demonstrated that statin therapy was associated with a significantly reduced risk of DVT. Additionally, previously experimental studies have also revealed that statin therapy remarkably reduced animal models of DVT $[18,19]$. Accordingly, our findings supported those from these two studies $[15,17]$.

Abundant studies have revealed that, other than its cholesterol-lowering effect, statin also possesses pleiotropic properties, especially those of anti-inflammation 


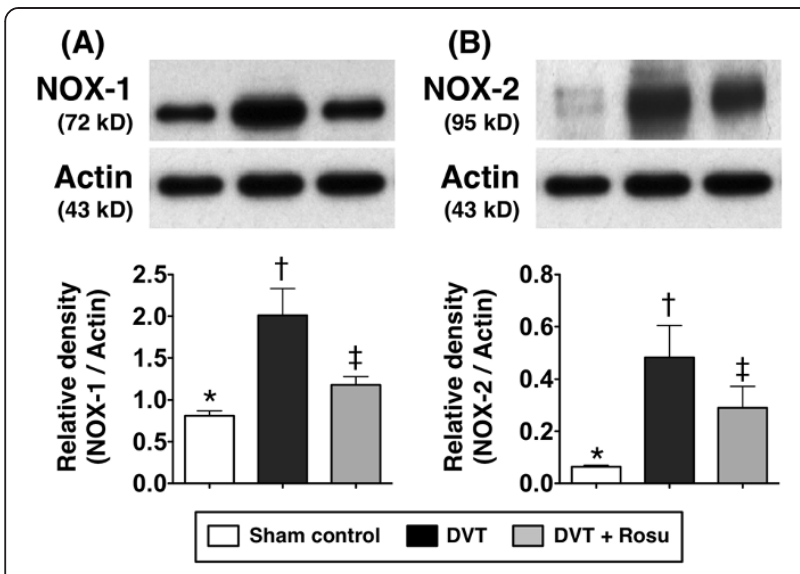

Figure 11 Protein expressions of reactive oxygen species (ROS) at day 14 after DVT-inducing procedure. A) Significantly higher protein expression of NOX-1 in group 2 than in groups 1 and 3 , and significantly in group in group 3 than in group 1. * vs. other groups with different symbols $\left({ }^{*},+, \neq\right), p<0.001$. B) Notably increased protein expression of NOX-2 in group 2 than in groups 1 and 3 , and significantly elevated in group 3 than in group 1. * vs. other groups with different symbols (*,,$\neq$ ), $p<0.001$. Statistical analysis in $\mathbf{A}$ ) and $\mathbf{B}$ ) using one-way ANOVA, followed by Bonferroni multiple comparison post hoc test. Symbols $(*,+, \neq)$ indicate significance (at 0.05 level). DVT = deep vein thrombosis, DVT + Rosu $=$ DVT + rosuvastatin.

and anti-oxidation [20-22]. Previous studies have shown that the pathogenic mechanisms of VTED are complex, including the participation of inflammatory cellular elements and pro-inflammatory cytokines, rather than the simple picture of Virchow's triad [9-14]. One principal finding in the present study is that time courses of flow cytometric results showed circulating level CD14+ and Ly-6G + cells are remarkably higher in DVT animals than that in SC animals. Another noteworthy finding in the present study is that not only the cellular (CD68+ cells) components, but also the molecular inflammatory component (protein expressions of MMP-9, TNF- $\alpha$ ) in IVC specimen was found to be significantly higher in DVT animals than that in SC animals. Of importance is that all of these components were notably reduced in DVT animals after receiving rosuvastatin treatment. Our findings, therefore, reinforced those of previous studies [9-14,20-22].

Interestingly, statin treatment has been shown to reduce the activity, differentiation and proliferation of cytotoxic $\mathrm{T}$ lymphocytes and the severity of graft-versus-host disease $[23,24]$. Therefore, statin has been suggested to shed some light on the pathogenesis of immunosuppressive graftversus-host disease [23,24]. An essential finding in the present study is that the number of immune response cells (CD3+/CD4+ helper T cells, CD3+/CD8+ cytotoxic T cells and CD4 + CD25 + Foxp3+ Tregs) were markedly increased in DVT animals compared with that in SC animals by days 2, 6 and 14 after IVC-stenosis procedure. In addition, the circulating level of WBC was also remarkably higher in DVT than that in the SC group at days 2 and 14 after the procedure. Consistently, the number of these inflammatory and immune response cells was remarkably reduced in DVT animals after rosuvastatin treatment. Our findings are consistent with those of previous studies [23,24].

One distinctive finding in the present study is that oxidative stress (i.e., level oxidized protein by Oxyblot analysis) and expressions of ROS indices (NOX-1, NOX-2) in IVC were remarkably increased in DVT animals, but were significantly reduced in DVT animals after rosuvastatin treatment. These findings corroborated those of previous studies [20-22].

Another finding of interest in the current study is that the prevalence of early or late MNC apoptosis in circulation was significantly augmented in DVT rats compared to that in the SC animals by days 2 and 14 after DVTinduction procedure. We suggest that these phenomena were caused by thrombus-induced generation of ROS and oxidative stress as well as the augmentation of inflammatory response that, in turn, participated in MNC damage. Recent studies [25,26] have shown that tissue damage elicits inflammatory reaction and activation of complement cascade, thereby causing further tissue damage/cell death, and irreversible MNC apoptosis in systemic circulation in the setting of acute arterial occlusive syndrome. In this way, our findings are compatible with those of previous studies [25,26]. Furthermore, the incidence of cellular apoptosis was significantly reduced in DVT animals after rosuvastatin treatment. Therefore, our findings reinforced those of recent reports $[25,26]$.

Thrombomodulin, which was originally identified in vascular endothelial cells, is an integral membrane protein widely expressed in a variety of cell types. Its physiological importance lies in its role as a cofactor for thrombin and its ability to suppress blood coagulation by converting thrombin into an anticoagulant enzyme from a procoagulant enzyme [27]. Thrombomodulin has been identified to possess indirect anti-inflammatory property $[28,29]$. Based on the results of previous studies [27-29] and the association between inflammation and enhancement of thrombus formation [11-15], we propose that the augmented cellular expression of thrombomodulin in DVT animals in the current study was the result of an enhancement of thrombomodulin generation in response to the inflammation and formation of thrombosis elicited by stenosis of IVC. Accordingly, our findings, in addition to supporting those of previous studies [11-15,27-29], could, at least in part, explain the effect of rosuvastatin treatment on attenuating thrombomodulin expression in IVC endothelial cells through suppressing the expressions of these inflammatory and oxidative biomarkers. 


\section{Study limitation}

This study has limitations. First, the therapeutic dosage of rosuvastatin in the current study was based on our previous report [16]. The effects of different dosages of rosuvastatin on its effectiveness in reducing the thrombus burden, however, were not investigated. Therefore, this study does not provide an optimal rosuvastatin dosage that produces maximal therapeutic impact with minimal side effects. Second, this study did not completely rule out that the model used in this work might carry a variation in thrombus burden, making this model vulnerable when treatment options were evaluated. Third, this study did not completely rule out the possibility of procedurerelated infection that would induce an increase in the circulating number of immune cells. Additionally, this study did not measure the different sample site for circulating numbers of blood counts, neutrophils and CD11b that have been reported to be readily influenced by different sites of measurement [30]. Finally, although the present study provided copious data, the exact mechanisms by which rosuvastatin suppressed thrombus formation in IVC remain unclear.

\section{Conclusion}

The results of the present study highlight that DVT augmented inflammation, ROS generation, and oxidative stress that are associated with an increased thrombus burden. On the other hand, rosuvastatin treatment significantly reduced thrombus burden in the IVC in a rodent model of DVT.

\section{Competing interests}

We declare that we have no financial and personal relationships with other people or organizations that can inappropriately influence our work, there is no professional or other personal interest of any nature or kind in any product, service and/or company that could be construed as influencing the position presented in, or the review of, the manuscript entitled, "Impact of rosuvastatin treatment on reduction of thrombus burden in rat acute inferior vena cava stenosis".

\section{Authors' contributions}

All authors have read and approved the final manuscript. KLC, HIL, HWC, and CKS designed the experiment, performed animal experiments, and drafted the manuscript. LTC, YLC, SYH, HTC, and HWC (Chang) were responsible for the laboratory assay and troubleshooting. HWC (Chen), CKS, SL, and HKY participated in refinement of experiment protocol and coordination and helped in drafting the manuscript.

\section{Acknowledgement}

This study is supported by a program grant from Chang Gung Memorial Hospital, Chang Gung University (grant no. CMRPG8B0691).

\footnotetext{
Author details

'Department of Anesthesiology, Kaohsiung Chang Gung Memorial Hospital and Chang Gung University College of Medicine, Kaohsiung, Taiwan. 2Division of Thoracic and Cardiovascular Surgery, Department of Surgery, Kaohsiung Chang Gung Memorial Hospital and Chang Gung University College of Medicine, Kaohsiung, Taiwan. ${ }^{3}$ Department of Internal Medicine, Division of Cardiology, Kaohsiung Chang Gung Memorial Hospital and Chang Gung University College of Medicine, Kaohsiung, Taiwan. ${ }^{4}$ Basic Science, Nursing Department, Meiho University, Pingtung, Taiwan. ${ }^{5}$ Center for Translational Research in Biomedical Sciences, Kaohsiung Chang Gung
}

Memorial Hospital and Chang Gung University College of Medicine, Kaohsiung, Taiwan. 'Department of Anatomy, Chang Gung University, Taoyuan, Taiwan. 'Department of Emergency Medicine, E-DA Hospital, I-Shou University, Kaohsiung, Taiwan. ${ }^{8}$ Division of Colorectal Surgery, Department of Surgery, Kaohsiung Chang Gung Memorial Hospital and Chang Gung University College of Medicine, Kaohsiung, Taiwan. ${ }^{9}$ Department of Biological Sciences, National Sun Yat-Sen University, Kaohsiung, Taiwan.

Received: 15 May 2013 Accepted: 27 August 2014

Published online: 12 September 2014

\section{References}

1. White RH: The epidemiology of venous thromboembolism. Circulation 2003, 107(23 Suppl 1):14-18.

2. Kearon C: Natural history of venous thromboembolism. Circulation 2003 , 107(23 Suppl 1):122-130.

3. Tick LW, Kramer MH, Rosendaal FR, Faber WR, Doggen CJ: Risk factors for post-thrombotic syndrome in patients with a first deep venous thrombosis. J Thromb Haemost 2008, 6(12):2075-2081.

4. Oglesby M, Fineberg SJ, Patel AA, Pelton MA, Singh K: The incidence and mortality of thromboembolic events in cervical spine surgery. Spine (Phila Pa 1976) 2013, 38:E521-527.

5. Silverstein MD, Heit JA, Mohr DN, Petterson TM, O'Fallon WM, Melton LJ 3rd: Trends in the incidence of deep vein thrombosis and pulmonary embolism: a 25-year population-based study. Arch Intern Med 1998, 158(6):585-593.

6. Heit JA: Venous thromboembolism: disease burden, outcomes and risk factors. J Thromb Haemost 2005, 3(8):1611-1617.

7. Naess IA, Christiansen SC, Romundstad P, Cannegieter SC, Rosendaal FR, Hammerstrom J: Incidence and mortality of venous thrombosis: a population-based study. J Thromb Haemost 2007, 5(4):692-699.

8. Anderson FA Jr, Spencer FA: Risk factors for venous thromboembolism. Circulation 2003, 107(23 Suppl 1):19-116.

9. Furie B, Furie BC: Mechanisms of thrombus formation. N Engl J Med 2008, 359(9):938-949.

10. Bagot $C N$, Arya $R$ : Virchow and his triad: a question of attribution. Br J Haematol 2008, 143(2):180-190.

11. Wolberg AS, Aleman MM, Leiderman K, Machlus KR: Procoagulant activity in hemostasis and thrombosis: Virchow's triad revisited. Anesth Analg 2012, 114(2):275-285.

12. Herbert JM, Savi P, Laplace MC, Lale A: IL-4 inhibits LPS-, IL-1 beta- and TNF alpha-induced expression of tissue factor in endothelial cells and monocytes. FEBS Lett 1992, 310(1):31-33.

13. Bevilacqua MP, Pober JS, Majeau GR, Fiers W, Cotran RS, Gimbrone MA Jr: Recombinant tumor necrosis factor induces procoagulant activity in cultured human vascular endothelium: characterization and comparison with the actions of interleukin 1. Proc Natl Acad Sci U S A 1986, 83(12):4533-4537.

14. Machlus KR, Cardenas JC, Church FC, Wolberg AS: Causal relationship between hyperfibrinogenemia, thrombosis, and resistance to thrombolysis in mice. Blood 2011, 117(18):4953-4963.

15. Glynn RJ, Danielson E, Fonseca FA, Genest J, Gotto AM Jr, Kastelein JJ, Koenig W, Libby P, Lorenzatti AJ, MacFadyen JG, Nordestgaard BG, Shepherd J, Willerson JT, Ridker PM: A randomized trial of rosuvastatin in the prevention of venous thromboembolism. N Engl J Med 2009, 360(18):1851-1861.

16. Yen $\mathrm{CH}$, Lin KC, Leu S, Sun CK, Chang LT, Chai HT, Chung SY, Chang HW, Ko SF, Chen YT, Yip HK: Chronic exposure to environmental contaminant nonylphenol exacerbates adenine-induced chronic renal insufficiency: role of signaling pathways and therapeutic impact of rosuvastatin. Eur J Pharm Sci 2012, 46(5):455-467.

17. Ray JG, Mamdani M, Tsuyuki RT, Anderson DR, Yeo EL, Laupacis A: Use of statins and the subsequent development of deep vein thrombosis. Arch Intern Med 2001, 161(11):1405-1410.

18. Patterson KA, Zhang X, Wrobleski SK, Hawley AE, Lawrence DA, Wakefield TW, Myers DD, Diaz JA: Rosuvastatin reduced deep vein thrombosis in ApoE gene deleted mice with hyperlipidemia through non-lipid lowering effects. Thromb Res 2013, 131(3):268-276.

19. Rodriguez AL, Wojcik BM, Wrobleski SK, Myers DD Jr, Wakefield TW, Diaz JA: Statins, inflammation and deep vein thrombosis: a systematic review. J Thromb Thrombolysis 2012, 33(4):371-382. 
20. Ridker PM, Danielson E, Fonseca FA, Genest J, Gotto AM Jr, Kastelein JJ, Koenig W, Libby P, Lorenzatti AJ, MacFadyen JG, Nordestgaard BG, Shepherd J, Willerson JT, Glynn RJ, Group JS: Rosuvastatin to prevent vascular events in men and women with elevated C-reactive protein. N Engl J Med 2008, 359(21):2195-2207.

21. Chartoumpekis D, Ziros PG, Psyrogiannis A, Kyriazopoulou V, Papavassiliou AG, Habeos IG: Simvastatin lowers reactive oxygen species level by Nrf2 activation via PI3K/Akt pathway. Biochem Biophys Res Commun 2010, 396(2):463-466.

22. Ridker PM, MacFadyen JG, Wolfert RL, Koenig W: Relationship of lipoprotein-associated phospholipase A (2) mass and activity with incident vascular events among primary prevention patients allocated to placebo or to statin therapy: an analysis from the JUPITER trial. Clin Chem 2012, 58(5):877-886.

23. Katznelson S, Wang XM, Chia D, Ozawa M, Zhong HP, Hirata M, Terasaki PI, Kobashigawa JA: The inhibitory effects of pravastatin on natural killer cell activity in vivo and on cytotoxic T lymphocyte activity in vitro. $J$ Heart Lung Transplant 1998, 17(4):335-340.

24. Li D, Li Y, Hernandez JA, Patenia R, Kim TK, Khalili J, Dougherty MC, Hanley PJ, Bollard CM, Komanduri KV, Hwu P, Champlin RE, Radvanyi LG, Molldrem JJ, Ma Q: Lovastatin inhibits T-cell proliferation while preserving the cytolytic function of EBV, CMV, and MART-1-specific CTLs. J Immunother 2010, 33(9):975-982.

25. Tsai $\mathrm{TH}$, Lin YC, Sun CK, Chung SY, Chai HT, Yang CH, Chen SM, Hang CL, Chen CJ, Chua S, Wu CJ, Leu S, Yip HK: Prognostic value of circulating dead monocytes in patients with acute st-elevation myocardial infarction undergoing primary percutaneous coronary intervention. Cardiology 2010, 117(2):131-139.

26. Sheu JJ, Chua S, Sun CK, Chang LT, Yen CH, Wu C, Fu M, Yip HK: Intra-coronary administration of cyclosporine limits infarct size, attenuates remodeling and preserves left ventricular function in porcine acute anterior infarction. Int J Cardiol 2011, 147(1):79-87.

27. Gerlitz B, Hassell T, Vlahos CJ, Parkinson JF, Bang NU, Grinnell BW: Identification of the predominant glycosaminoglycan-attachment site in soluble recombinant human thrombomodulin: potential regulation of functionality by glycosyltransferase competition for serine474. Biochem J 1993, 295(Pt 1):131-140.

28. Raife TJ, Dwyre DM, Stevens JW, Erger RA, Leo L, Wilson KM, Fernandez JA, Wilder J, Kim HS, Griffin JH, Maeda N, Lentz SR: Human thrombomodulin knock-in mice reveal differential effects of human thrombomodulin on thrombosis and atherosclerosis. Arterioscler Thromb Vasc Biol 2011, 31(11):2509-2517.

29. Li YH, Kuo CH, Shi GY, Wu HL: The role of thrombomodulin lectin-like domain in inflammation. J Biomed Sci 2012, 19:34.

30. Nemzek JA, Bolgos GL, Williams BA, Remick DG: Differences in normal values for murine white blood cell counts and other hematological parameters based on sampling site. Inflamm Res 2001, 50(10):523-527.

doi:10.1186/s12950-014-0027-2

Cite this article as: Lin et al:: Impact of rosuvastatin treatment on reduction of thrombus burden in rat acute inferior vena cava stenosis. Journal of Inflammation 2014 11:27.

\section{Submit your next manuscript to BioMed Central and take full advantage of:}

- Convenient online submission

- Thorough peer review

- No space constraints or color figure charges

- Immediate publication on acceptance

- Inclusion in PubMed, CAS, Scopus and Google Scholar

- Research which is freely available for redistribution 